\title{
Property of TS-16N Solid State Nuclear Track Detectors as an Imaging Medium for Macroautoradiography of $\boldsymbol{a}$-Emitters in Biological Specimens
}

\author{
Nobuhito IsHIGURE and Osamu MATSUOKA \\ Division of Comparative Radiotoxicology, National Institute of Radiological Sciences \\ 9-1, Anagawa-4-chome, Chiba-shi 260, Japan \\ Received September 8, 1987
}

Feasibility of TS-16N solid state nuclear track detectors for an imaging medium of rapid autoradiography of $\alpha$-emitters is described. Though a little longer etching time was required, the contrast of autoradiographic image on this detector proved to be superior to CR-39 detectors whose property for macroautoradiography was previously reported by the authors. The resolutions of these two different type detectors were almost equivalent to each other. The autoradiography taken by way of trial proved that this detector could be used to study metabolism and dosimetry of internally deposited $\alpha$-emitters. With further study, the inherent properties of this detector such as low background or high sensitivity should extend the field of track etch imaging technique such as fast neutron radiography.

Key Words: TS-16N-solid state nuclear track detector, imaging medium, macroautoradiography, $\alpha$-emitters, biological specimens

\section{Introduction}

We previously reported ${ }^{1,2)}$ that CR-39 detectors could be applied to macroautoradiography of specimens containing $\alpha$-emitters. The autoradiographic image in this method is produced by the scattered light from the etch pits, which reflects the pattern of the distribution of etch pit densities. This method can reduce exposure time to $1 / 20$ of that required with a conventional technique. Unlike photographic films, in addition, handling in the dark becomes needless. However, the quality is not always good enough to be used as an imaging medium. Many small track-like pits sometimes appear on a CR-39 detector after etching". Since the defused reflection of light by these spurious pits makes the background brighter, we have to select good plates of CR-39 which are suited for the imaging medium after trial use.

Quite recently another type solid state nu-

* TS- $16 \mathrm{~N}$ is the trade name of poly-allyl diglycol carbonate supplied by Nagase-Landauer Ltd. (Tokyo, Japan). clear track detector of allyl diglycol carbonate named as TS- $16 \mathrm{~N}^{*}$ was developed. A main purpose to be used is monitoring service for neutron exposure. A report tells that the density of background etch pits is extremely ${ } \mathrm{low}^{4}$. Since this detector is developed to be used properly as a solid state nuclear track detector, we can expect to obtain the detectors which are produced under careful quality control.

We obtained six different plates of TS- $16 \mathrm{~N}$ which were made with different curing conditions on trial basis. Properties of this detector as an imaging medium for $\alpha$-autoradiography were examined by comparing with those of CR-39 detectors.

\section{Results and Discussion}

$2 \cdot 1$ Fundamental etching properties of TS$16 \mathrm{~N}$ detector

2.1.1 Bulk etching rate

The detectors were etched in a $27 \%$ solution of sodium hydroxide kept at $70^{\circ} \mathrm{C}$ by a water bath. A doubly lidded polyethylene bottle was used for an etching container to keep the 
Table 1 Bulk etching rate of TS-16N and CR-39 detectors

\begin{tabular}{lcc}
\hline \multicolumn{1}{c}{ Detector } & $\begin{array}{c}\text { Removed thickness* } \\
(\mu \mathrm{m})\end{array}$ & $\begin{array}{c}V_{\mathbf{B}}{ }^{* *} \\
(\mu \mathrm{m} / \mathrm{h})\end{array}$ \\
\hline CR-39 & 39.50 & 3.29 \\
TS-16N No. 1 & 30.67 & 2.56 \\
No. 2 & 30.83 & 2.57 \\
No. 3 & 30.83 & 2.57 \\
No. 4 & 30.17 & 2.51 \\
No. 5 & 32.00 & 2.67 \\
No. 6 & 32.33 & 2.69 \\
\hline
\end{tabular}

* Average of three samples of each detector

** Etching time was 6 hours

etchant concentration constant, otherwise it should easily be changed by evaporation of the solvent and/or absorption of the ambient vapor. Bulk etching rate was obtained by measuring detector thicknesses before and after etching with a precise micrometer. All detectors were dried in a box containing silica gel before thickness measurement, because the absorbed water swelled the detectors. The results are shown in Table 1.

The bulk etching rate of every TS- $16 \mathrm{~N}$ detector was obviously smaller than that of the CR39 detector. We considered that the manufacturer polymerized these detectors more solidly than CR-39 to keep the surface smooth even after etching. The bulk etching rates of detectors No. 1 to No. 3 were close to each other. The detector No. 4 showed a little smaller bulk etching rate than the others. As to No. 5 and No. 6, the two bulk etching rates were nearly the same to each other. The six different detectors appeared to be grouped into (1) No. 1 to No. 3, (2) No. 4 and (3) No. 5 and No. 6.

\subsubsection{Etch pit diameter}

The detectors were irradiated with $\alpha$ particles emitted from a vacuum-evaporated source of ${ }^{241} \mathrm{Am}$. These $\alpha$-particles were nearly normally incident to the detector through a collimator. The air between the source and the detector degraded the energy into $4.9 \mathrm{MeV}$. The detectors were etched so that $9.9 \mu \mathrm{m}$ surfaces were removed in each face by bulk etching. The diameter of etch pit thus developed was measured with an image process-
Table 2 Development of etch pit diameter

\begin{tabular}{|c|c|c|c|c|c|}
\hline Dete & ctor & $\begin{array}{l}\text { Etching } \\
\text { time }\end{array}$ & $\begin{array}{l}V_{\mathbf{B}} \cdot t \\
(\mu \mathrm{m})\end{array}$ & $\begin{array}{l}\text { Diameter } \\
(\mu \mathrm{m})\end{array}$ & $\frac{V_{\mathrm{T}}}{V_{\mathrm{B}}}-1$ \\
\hline CR-39 & & $3 \mathrm{~h}$ & 9.87 & $9.84 \pm 0.07$ & 0.67 \\
\hline \multirow[t]{6}{*}{ TS-16N } & No. 1 & $3 \mathrm{~h} 52 \mathrm{~min}$ & 9.90 & $9.88 \pm 0.08$ & 0.66 \\
\hline & No. 2 & $3 \mathrm{~h} 51 \mathrm{~min}$ & 9.89 & $10.1 \pm 0.11$ & 0.70 \\
\hline & No. 3 & $3 \mathrm{~h} 51 \mathrm{~min}$ & 9.89 & $9.64 \pm 0.09$ & 0.62 \\
\hline & No. 4 & $3 \mathrm{~h} 56 \mathrm{~min}$ & 9.87 & $10.4 \pm 0.09$ & 0.76 \\
\hline & No. 5 & $3 \mathrm{~h} 42 \mathrm{~min}$ & 9.88 & $10.8 \pm 0.09$ & 0.85 \\
\hline & No. 6 & $3 \mathrm{~h} 40 \mathrm{~min}$ & 9.86 & $10.9 \pm 0.08$ & 0.87 \\
\hline
\end{tabular}

ing video device connected to an optical microscope ${ }^{6}$. The results are shown in Table 2. Compared with the CR-39 detector, the diameters were nearly the same for No. 1 to No. 3, a little larger for No. 4 and obviously larger for No. 5 and No. 6.

Assuming for simplicity that bulk etching rate $V_{B}$ is constant and isotropic and also that track etching rate $V_{\mathrm{T}}$ is constant over the length $V_{\mathrm{T}} \cdot t$ etched in time $t$, then etch pit diameter $D$ can be shown as

$$
\left.D=2 V_{\mathbf{B}} \cdot t\left(V_{\mathbf{T}} / V_{\mathbf{B}}-1\right) /\left(V_{\mathbf{T}} / V_{\mathbf{B}}+1\right)\right\}^{1 / 2} \quad \text { I }(1)
$$

By substituting the measured diameter and bulk etching rate into this equation, sensitivities $V_{\mathrm{T}} / V_{\mathrm{B}}-1$ were obtained as shown in the last column of Table 2. We can suppose as a temporary measure that the sensitivities of TS$16 \mathrm{~N}$ detectors were not lower than that of the CR-39 detector used here.

\subsubsection{Detection probability}

The detectors were irradiated with $\alpha$-particles by contacting with a ${ }^{241} \mathrm{Am}$ source. These detectors were etched so that $20 \mu \mathrm{m}$ surfaces were removed in each face by bulk etching, which agreed to the etching condition standardized so far when the technique using CR-39 was initially developed. The measured etch pit density was divided by the activity density and by the irradiation time to obtain detection probability. The results are shown in Table 3. The detection probabilities of six different TS$16 \mathrm{~N}$ and one CR-39 detectors were nearly the same to each other for the etching condition employed here. This also supported that the sensitivity of TS-16N was not lower than that of CR-39. 
Table 3 Detection probability

\begin{tabular}{|c|c|c|c|c|}
\hline Detect & & Etching time & $\begin{array}{l}V_{\mathrm{B}} \cdot t \\
(\mu \mathrm{m})\end{array}$ & $\begin{array}{c}\text { Detect. probab. } \\
(\%)\end{array}$ \\
\hline CR-39 & & $6 \mathrm{~h}$ & 19.8 & $32.0 \pm 1.2$ \\
\hline \multirow[t]{6}{*}{ TS-16N } & No. & $7 \mathrm{~h} 46 \mathrm{~min}$ & 19.9 & $31.8 \pm 1.2$ \\
\hline & No. & $7 \mathrm{~h} 46 \mathrm{~min}$ & 20.0 & $32.3 \pm 1.2$ \\
\hline & No. & $7 \mathrm{~h} 46 \mathrm{~min}$ & 20.0 & $30.8 \pm 1.1$ \\
\hline & No. & $7 \mathrm{~h} 46 \mathrm{~min}$ & 19.5 & $32.3 \pm 1.2$ \\
\hline & No. & $7 \mathrm{~h} 22 \mathrm{~min}$ & 19.7 & $31.0 \pm 1.1$ \\
\hline & No. & $7 \mathrm{~h} 22 \mathrm{~min}$ & 19.8 & $31.1 \pm 1.1$ \\
\hline
\end{tabular}

2.2 Quality of autoradiographic image on TS-16N detectors

\section{$2 \cdot 2 \cdot 1$ Contrast}

As mentioned in chapter 1 , the autoradiographic image is produced by the scattered light from the etch pits. Hence, the contrast of the image should be examined for the reflected light from the autoradiograph.

Detectors were irradiated with $\alpha$-particles by contacting with the ${ }^{241} \mathrm{Am}$ source; the fluence of $\alpha$-particles incident to the detector was 18000 particles per $\mathrm{mm}^{2}$. After etching, the intensity of reflected light was measured with a micro-densitometer in reflection mode: $45^{\circ}$ incidence and $0^{\circ}$ acceptance of light. The results are shown in Fig. 1.

The backgrounds of TS- $16 \mathrm{~N}$ detectors were nearly constant for any etching times. In addition they showed small batch variation between them. These results indicated that the detector surfaces were kept smooth even after such a long etching in any TS-16N detectors. As to the CR-39 detectors, on the other hand, the backgrounds were much different from detector to detector. They were, to make matters worse, all higher than those of TS- $16 \mathrm{~N}$ detectors; in other words, the background was brighter in CR-39 than in TS-16N.

The light intensities from etch pit area (for simplicity, hereafter referred as signals) increased with etching time in any detectors of TS-16N and CR-39. This is because $\alpha$-tracks were developed and grew with progression of etching. The signals of detectors No. 1 to No. 4 were very close to each other. As to the detectors of No. 5 and No. 6, the two signals were nearly the same to each other, and they

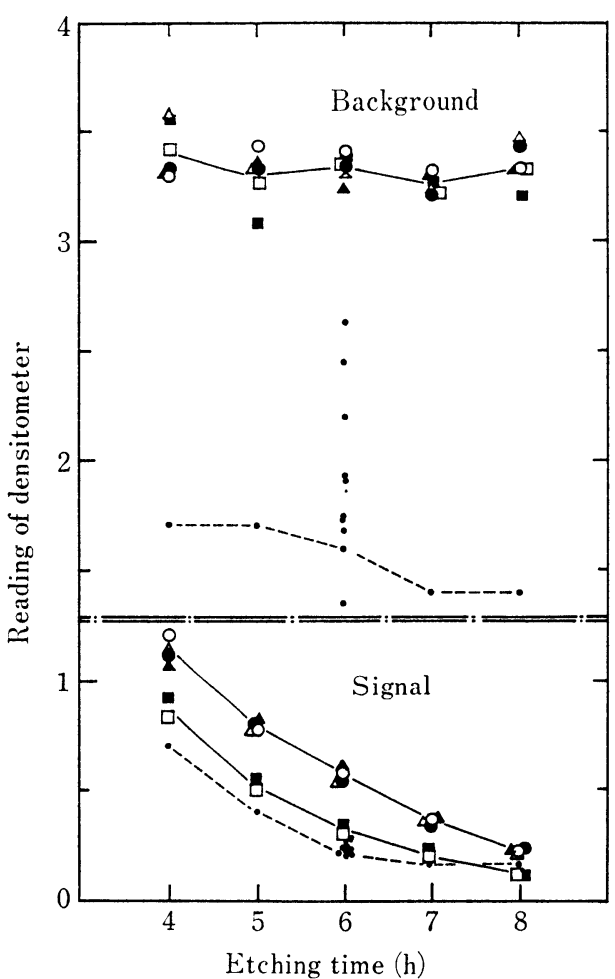

Fig. 1 Reflection of light from background and etch pit areas; $\bigcirc$ : TS- $16 \mathrm{~N}$ No. 1, $\mathrm{O}$ No. $2, \triangle$ : No. $3, \Delta$ : No. $4, \square$ : No. 5 $\square$ : No. 6 and $\cdot$ : CR-39 detectors.

The ordinate shows $\log \left(I_{1} / I_{\mathrm{r}}\right)+C$, where $I_{1}$ is intensity of incident light, $I_{r}$ is that of reflected light and $C$ is constant.

were higher than those of the group of No. 1 to No. 4. As mentioned in section $2 \cdot 1$, the fundamental etching properties were very close to each other between the detectors No. 1 to No. 3 and between No. 5 and No. 6 . It is hence quite reasonable that the signals were close within each group of detectors. In case of the detector No. 4, etch pits grew at a little higher rate than the group of No. 1 to No. 3, which probably compensated a little smaller bulk etching rate.

The signals of CR-39 detectors were higher than those of TS- $16 \mathrm{~N}$ detectors; the values of 6 hour etched CR-39 detectors were equivalent to those of No. 1 to No. 4 etched for 7.8 hours and also those of No. 5 and No. 6 for 6.7 hours. From Table 2, the etch pit grew at $3.28 \mu \mathrm{m} / \mathrm{h}$ for CR-39 detectors, $2.57 \mu \mathrm{m} / \mathrm{h}$ for No. 1 to No. 4 and $2.94 \mu \mathrm{m} / \mathrm{h}$ for No. 5 
and No. 6. Therefore, the detectors No. 1 to No. 4 must be etched for 7.7 hours and the detectors No. 5 and No. 6 for 6.7 hours to grow up to the same diameter to that of 6 hour etched CR-39 detector; they were the same etching times as required to give the same signals in these detectors.

The contrast was evaluated by subtracting the signal from the background for the values of 7.8 hour etching for No. 1 to No. 4, 6.7 hour etching for No. 5 and No. 6, and 6 hour etching for the CR-39 detectors. The average for the six TS-16N detectors was 3.09 and the standard deviation of them was 0.07. As to the CR-39 detectors, on the other hand, the contrasts were distributed between 1.09 and 2.41; the average of the ten detectors was 1.69 and the standard deviation of them was 0.40. We can thus conclude that TS-16N detectors give a contrast superior to CR-39 detectors, which is higher than three, that is, one thousand fold in terms of light intensity.

\subsubsection{Resolution}

A resolution test chart for $\mathrm{X}$-rays was used. This chart was made of a sheet of gold foil, $15 \mu \mathrm{m}$ in thickness, on which there were several sets of three narrow parallel rectangular channels cut at stated intervals.

Resolution depends on the shape as well as the size of etch pits. To characterize the etch pits observed in autoradiograph, the size of longer axis and the ratio of longer vs. shorter axes of etch pits were measured for the CR-39 detector contacted with an autoradiographic specimen. The longer axis was, as a result, $23.2 \pm 1.5 \mu \mathrm{m}$ (mean \pm S.D.) and the ratio was $1.22 \pm 0.16$ (mean \pm S.D.).

Since the CR-39 detector contacted directly with the ${ }^{241} \mathrm{Am}$ source gave a different character of etch pits: the longer axis of 26.5 \pm $3.7 \mu \mathrm{m}$ and the ratio of $2.08 \pm 1.09$, we had to find the energy absorber which gave the same etch pit character as seen in autoradiograph. The detectors were irradiated through various kinds of polymer films. The axes of the obtained etch pits were measured. As a result, a thin film of polyvinylidene chloride for kitchen use was found to be an adequate absorber; the longer axis was $23.4 \pm 1.4 \mu \mathrm{m}$ and the ratio

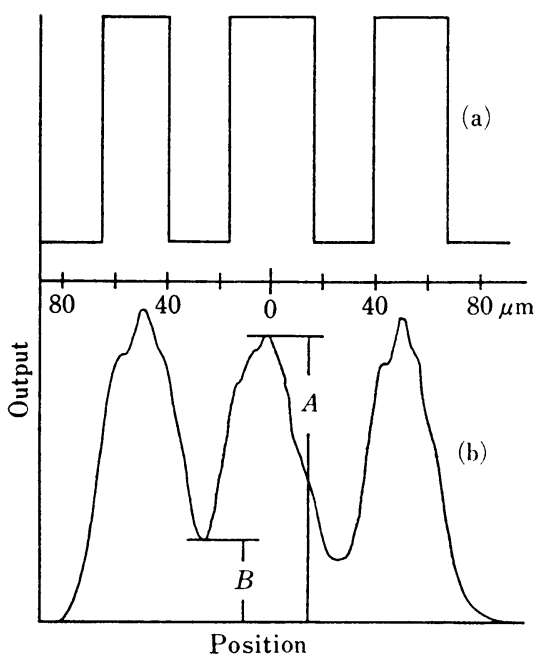

Fig. 2 Diagram showing response of TS-16N detectors; (a) original square pattern of test chart and (b) sinusoidal wave pattern modulated by the response characteristics of detector.

was $1.25 \pm 0.11$. The detectors were hence irradiated with putting the test chart and the polymer film between the detectors and the $\alpha$-source.

As an objective measure of resolution, MTF (modulation transfer function) was evaluated. When the image of the test pattern on the detector was scanned with the micro-densitometers in transmission mode, the original square wave pattern as shown in Fig. 2(a) was modulated into the sinusoidal wave pattern as in (b) by the response characteristics of the detectors. Modulation transfer function was evaluated from the equation

$$
\mathrm{MTF}=(A-B) /(A+B) \text {, }
$$

where $A$ and $B$ are the values of top and bottom of the characteristic wave pattern, respectively. The results are plotted in Fig. 3 as a function of the spatial frequency of the test chart; the spatial frequency means the number of line pairs that can be drawn within a given spatial interval, normally $1 \mathrm{~mm}$.

At the same spatial frequency the MTF decreased with the etching. This is because etch pits became larger with etching. In a middle region of the frequencies, the MTF of TS-16N was a little smaller than that of CR-39 detector. At higher frequencies, on the 


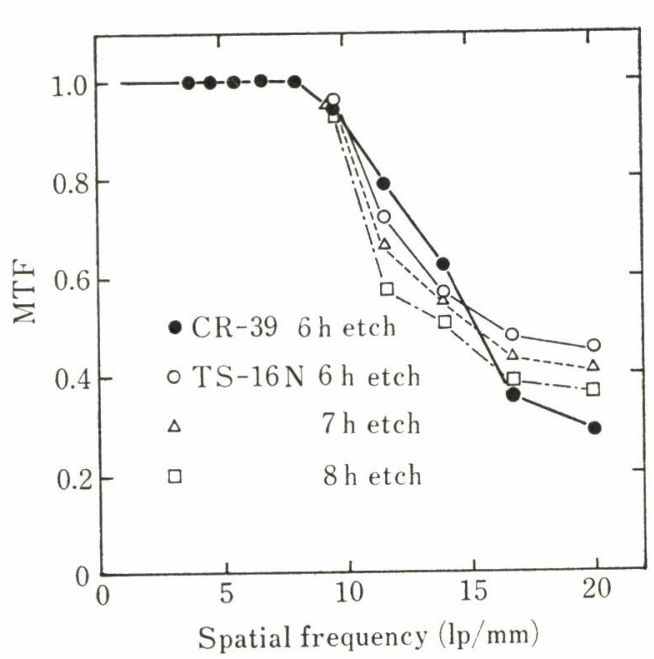

Fig. 3 Modulation transfer function plotted as a function of spatial frequency of test chart.

other hand, TS- $16 \mathrm{~N}$ a little surpassed CR-39. On a whole, we can conclude that the resolutions of these two different type detectors are almost equivalent to each other.

To demonstrate the resolution attained in this method, images of fine grid mesh were taken on TS-16N detectors. As shown in Fig. 4 the checkered pattern is clearly seen for 200 and 300 meshes.

\subsection{Example of macro-autoradiograph}

Plates of TS-16N were exposed to freezedried sections of lungs isolated from the rats which were inhaled with ${ }^{239} \mathrm{Pu}$ nitrate. The autoradiographs obtained after 7.8 hour etching are shown in Fig. 5; (a) is for the rat sacrificed after 3 hours from inhalation and

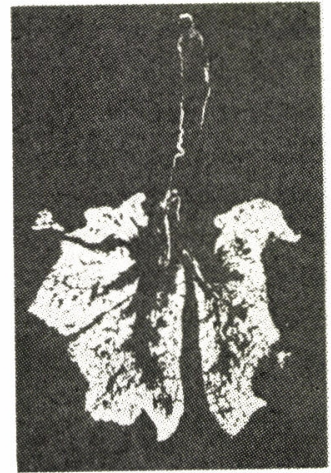

(a)

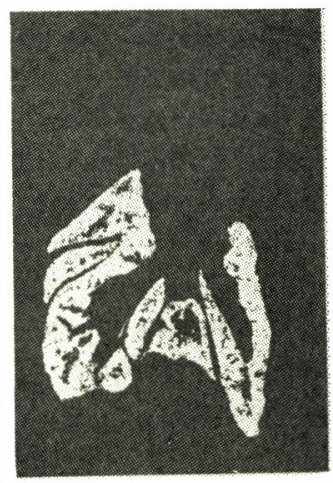

(b)
Fig. 5 Autoradiographs of $40 \mu \mathrm{m}$ thick sections of rat lungs inhaled with ${ }^{239} \mathrm{Pu}$ nitrate; (a) for the rat sacrificed after 3 hours from inhalation and (b) after one month.

(b) one month. The exposure times were 4 hours for (a) and 1 day for (b); with a conventional technique, on the other hand, 4 days for (a) and 2 weeks for (b) were required.

It is clearly seen that the plutonium initially deposited on both regions of tracheo-bronchial ( $\mathrm{T}-\mathrm{B})$ and pulmonary, and then the $\mathrm{T}-\mathrm{B}$ region was mostly cleared one month later, though a small fraction of radioactivity still remained on the pulmonary region. From such a distinct image of autoradiograph, we can expect to use this detector to study metabolism or dosimetry of internally deposited $\alpha$-emitters in experimental animals.

\section{Conclusions}

Detectors of TS-16N are much superior to CR-39 in the contrast of autoradiographic image. This is because the spurious pits some-

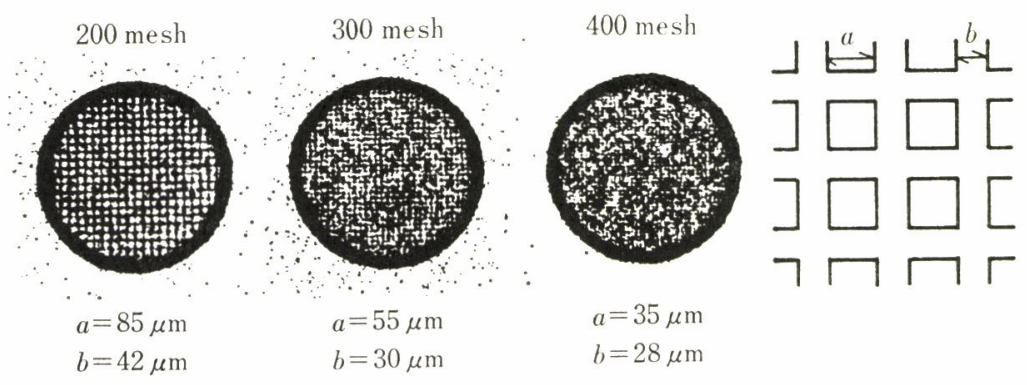

Fig. 4 Images of fine grid mesh taken on TS-16N detectors by etch pits of $\alpha$-particles. 
times seen on CR-39 detectors are very few on this detector, by which the detector surface is kept smooth even after long etching. The resolutions of these two different type detectors are almost equivalent to each other.

We can use this detector to study metabolism and dosimetry of internally deposited $\alpha$-emitters, which has been proved by distinct autoradiographic images of rat lungs inhaled with $\alpha$-emitters.

With further study, in addition, the inherent properties of this detector such as low background or high sensitivity should extend the field of track etch imaging technique such as fast neutron radiography.

\section{References}

1) Ishigure, N.: Radioisotopes, 34, 101-102 (1985)

2) Ishigure, N.: Hoshasen (Ionizing Radiation), 12, 100-105 (1985) (in Japanese)

3) Ishigure, N. and Matsuoka, O.: Hoken Butsuri (J. Jpn. Health Phys. Soc.), 22, 287-293 (1987)

4) Nomura, Y., Miyabe, K., Koizumi, K. and Yamato, A.: Abstracts of the 22nd Meeting of Jpn. Health Phys. Soc., 7 (1987) (in Japanese)

5) Ishigure, N.: Hoken Butsuri (J. Jpn. Health Phys. Soc.), 20, 43-48 (1985) (in Japanese)

要 旨

\title{
$\boldsymbol{a}$ 放射体のマクロオートラジオグラフィにおける 固体飛跡検出器 TS-16N の撮像桇体としての特性
}

\author{
石榑信人，松岡 理 \\ 放射線医学総合研究所内部被ばく研究部 \\ 260 千葉市穴川4-9-1
}

\footnotetext{
$\alpha$ 放射体のマクロオートラジオグラフィに対する固体飛跳検出器 TS-16N の適用性を述べた。 以前に報告した CR-39 に比し，TS-16N のコントラストは格段に高いことが分かった。これは， ハッッグラウンドがきわめて低いことによるすのである。分解能は同等であった。なおエッチング には若干長い時間を必要とした。試みに実施したオートラシオオグフィは， $\alpha$ 放射体による内部被 曝の生物学的研究にこの検出器が充分応用できることを示した。
} 